\title{
TIPO DE LUZ NA MULTIPLICAÇÃO IN VITRO DE FRAMBOESEIRA (Rubus idaeus L.) 'BATUM'
}

\author{
ALAN CRISTIANO ERIG ${ }^{2}$ \& MÁRCIA WULFF SCHUCH ${ }^{3}$
}

\begin{abstract}
RESUMO - O objetivo deste trabalho foi determinar um possível tipo de luz mais ativo que a luz branca, de forma a aumentar a eficiência da multiplicação in vitro de framboeseira 'Batum', em relação ao número de brotos, de folhas e a taxa de multiplicação. Para isso, os tratamentos consistiram em cinco diferentes tipos de luz sob os quais os explantes cresceram (branca - testemunha, vermelha, amarela, azul e verde), fornecidas por meio da modificação do espectro luminoso das lâmpadas fluorescentes brancas-frias, utilizando filtros coloridos de acetato celulose, do tipo Lee Filters (Walworth Ind. Estate, Andover, England). O meio de cultura constituiu-se dos sais e vitaminas de MS, adicionado de mioinositol (100mgL' $\left.{ }^{1}\right)$, sacarose $\left(30 \mathrm{gL}^{-1}\right)$, ágar $\left(6 \mathrm{gL}^{-1}\right)$ e de BAP $(4,44 \mu \mathrm{M})$. A eficiência da multiplicação in vitro de framboeseira 'Batum', em relação às variáveis analisadas, aumentou com a utilização da luz verde. A luz vermelha também incrementou o número médio de brotos; no entanto, sua morfologia foi modificada, com uma menor expansão das folhas, os brotos finos e os entrenós alongados.
\end{abstract}

Termos para indexação: cultura de tecidos, espectro luminoso, framboesa, pequenas frutas.

\section{LIGHT TYPE IN THE IN VITRO MULTIPLICATION OF RASPBERRY PLANTS (Rubus idaeus L.) 'BATUM'}

ABSTRACT - The aim of this work was to determine a possible light type more active than the white light, in way to increase the efficiency of the in vitro multiplication of raspberry 'Batum', in relation to the shoots and leaves number, and the multiplication rate. For that, the treatments consisted of five different light types (white - control, red, yellow, blue and green), under which the explants grew, supplied through the modification of the luminous spectrum of the white-cold fluorescent lamps, using colored filters of acetate cellulose, Lee Filters type (Walworth Ind. Estate, Andover, England). The culture medium was constituted of MS salts and vitamins, added of myo-inositol $\left(100 \mathrm{mgL}^{-1}\right)$, sucrose $\left(30 \mathrm{gL}^{-1}\right)$, agar $\left(6 g L^{-1}\right)$ and BAP $(4.44 \mu \mathrm{M})$. The efficiency of the in vitro multiplication of raspberry 'Batum', in relation to the analyzed variables, increased with the use of green light. The red light also increased the shoots mean number, however, its morphology was modified, with a smaller leaves expansion, thin shoots and prolonged internodes.

Index terms: tissue culture, luminous spectrum, raspberry, small fruits.

\section{INTRODUÇÃO}

A framboeseira (Rubus idaeus L.) pertence à família das Rosáceas, sendo originária do centro e norte da Europa e de parte da Ásia (Raseira et al., 2004). No Brasil, a cultura da framboesa foi introduzida na região de Campos do Jordão - SP, e atualmente, os principais Estados produtores são Rio Grande do Sul, São Paulo e Minas Gerais, com área de cultivo estimada em 40 hectares (Pagot \& Hoffmann, 2003). Entre as cultivares já testadas no Brasil, destaca-se a cultivar Batum, que se caracteriza pela baixa exigência em frio, tipo remontante e com frutos de formato oval (Raseira et al., 2004).

A micropropagação tem sido usada com sucesso, não só para plantas que normalmente se reproduzem vegetativamente (Grattapaglia \& Machado, 1998), como a framboeseira, por exemplo, que é comumente propagada por rebentos, raízes que emitem novos brotos ou por meio da estaquia herbácea (Alárcon, 2004), como também para outras espécies onde esse tipo de reprodução é difícil, possibilitando a multiplicação rápida e em período de tempo e espaço físico reduzidos (Grattapaglia \& Machado, 1998).

A luz é um fator fundamental para as plantas, pela ação direta ou indireta na regulação de seu crescimento e desenvolvimento (Morini \& Muleo, 2003). As respostas da planta não dependem apenas de ausência ou presença de luz, mas também da variação em qualidade luminosa (Felippe, 1986). Para otimizar a captação da energia luminosa para a fotossíntese, as plantas desenvolveram uma série de fotorreceptores que regulam seu crescimento e desenvolvimento em relação à presença, quantidade, direção, duração e qualidade da radiação luminosa incidente (Morini \& Muleo, 2003).

Na cultura de tecidos de plantas, a fonte de luz geralmente utilizada na sala de crescimento é a lâmpada fluorescente branca-fria
(Kim et al., 2004), citada em 90\% dos trabalhos científicos (Kodym \& Zapata-Arias, 1999). Poucos estudos têm sido realizados buscando compreender o efeito da qualidade da luz no crescimento e desenvolvimento dos tecidos de espécies lenhosas cultivados in vitro. Entretanto, estes têm demonstrado que a qualidade da luz influencia a eficiência biológica dos fitorreguladores adicionados ao meio de cultura, bem como o balanço hormonal nos tecidos. Conseqüentemente, a qualidade da luz surge como uma ferramenta na manipulação da indução de balanços fisiológicos favoráveis a respostas específicas no crescimento das plantas (Morini \& Muleo, 2003).

Na multiplicação in vitro da planta medicinal Alternanthera brasiliana L., a maior taxa de multiplicação foi obtida cultivando-a em meios livres de fitorreguladores e sob radiação na faixa do azul ou do verde do espectro luminoso (Luca et al., 2001). Os melhores resultados para a taxa de proliferação de Prunus GF 655-2 cultivados em meio de cultura com 2,7 $\mu \mathrm{M}$ de benziladenina (BA) foram obtidos utilizando luz branca, enquanto a luz vermelha e a azul mostraram resultados inferiores (Baraldi et al., 1988). A proliferação e o alongamento dos explantes de porta-enxertos para Prunus spp., da série de clones I.S., foram favorecidos pela utilização de luz incandescente (Rossi et al., 2002). No cultivo in vitro do porta-enxerto de macieira MM106, a luz verde proporcionou a maior taxa de proliferação de brotos (Casano, 1995).

O objetivo deste trabalho foi determinar um possível tipo de luz mais ativo que a luz branca, de forma a aumentar a eficiência da multiplicação in vitro de framboeseira (Rubus idaeus L.) 'Batum', em relação ao número de brotos, de folhas e a taxa de multiplicação.

\section{MATERIAL E MÉTODOS}

O trabalho foi realizado no Laboratório de Micropropagação

${ }^{1}$ (Trabalho 028/2005). Recebido: 23/02/2005. Aceito para publicação: 29/09/2005.

${ }^{2}$ Engenheiro Agrônomo, Dr., Bolsista Pós-Doutorado do CNPq. Laboratório de Micropropagação de Plantas Frutíferas, Departamento de Fitotecnia, Faculdade de Agronomia Eliseu Maciel (FAEM) / Universidade Federal de Pelotas (UFPel). Caixa Postal 354, CEP 96.010-900, Pelotas-RS. E-mail: acerig@ufpel.tche.br. Autor para correspondência.

${ }^{3}$ Engenheira Agrônoma, Dra., Professora do Departamento de Fitotecnia, FAEM / UFPel. Caixa Postal 354, CEP 96.010-900, Pelotas, RS. E-mail: marciaws@ufpel.tche.br.

Apoio do MCT/CNPq. 
de Plantas Frutíferas do Departamento de Fitotecnia da FAEM / UFPel, em Pelotas - RS. Os tratamentos consistiram de cinco diferentes tipos de luz sob os quais os explantes cresceram (branca - testemunha, vermelha, amarela, azul e verde). Segmentos caulinares com três gemas, sem o ápice caulinar e as folhas, provenientes de framboeseiras (Rubus idaeus L.) 'Batum' cultivadas in vitro, foram utilizados como explantes. O delineamento experimental inteiramente casualizado foi o utilizado, com quatro repetições por tratamento, sendo cada repetição constituída de um frasco com cinco explantes.

Os diferentes tipos de luz foram fornecidos por meio da modificação do espectro luminoso das lâmpadas fluorescentes brancasfrias, utilizando filtros coloridos de acetato celulose, do tipo Lee Filters (Walworth Ind. Estate, Andover, England), com as seguintes especificações: azul (número 120 Deep blue), verde (número 738 Jas green), amarelo (número 105 Orange) e vermelho (número 106 Primary red). Os filtros foram colocados sobre os frascos de cultivo, que foram mantidos em sala de crescimento, com 16 horas de fotoperíodo, temperatura de $25 \pm 2^{\circ} \mathrm{C}$ e densidade de fluxo de fótons do período de luz de $42 \mu \mathrm{molm}^{-2} \mathrm{~s}^{-1}$. Para o tratamento luz branca (testemunha), os frascos não foram cobertos pelo filtro.

O meio de cultura utilizado constituiu-se dos sais e vitaminas de MS (Murashige \& Skoog, 1962), com 100 $\mathrm{mgL}^{-1}$ de mioinositol, 30gL ${ }^{1}$ de sacarose e adicionado de $4,44 \mu \mathrm{M}$ de 6 -benzilaminopurina (BAP). $\mathrm{O}$ pH foi ajustado para 5,8 antes da inclusão do ágar na concentração de $6 \mathrm{gL}^{-1} \mathrm{e}$, posteriormente, autoclavado a $121^{\circ} \mathrm{C}$ e $1,5 \mathrm{~atm}$, por 20 minutos. Foram utilizados frascos de $250 \mathrm{~mL}$ com $30 \mathrm{~mL}$ de meio de cultura.

Aos 45 dias de cultivo, foram avaliados o número de brotos, de folhas e de gemas por explante. A partir do número de gemas, determinou-se a taxa de multiplicação, dividindo-se o número de gemas por explante obtido aos 45 dias de cultivo, pelo número inicial de gemas do explante no estabelecimento do experimento (três gemas). Os dados foram submetidos à análise de variância e as médias dos tratamentos, comparadas estatisticamente pelo teste de Duncan, em nível de 5\% de probabilidade, através do programa estatístico SANEST (Zonta \& Machado, 1987)

\section{RESULTADOS E DISCUSSÃO}

O tipo de luz teve efeito significativo sobre as três variáveis avaliadas (número médio de brotos, número médio de folhas e taxa de multiplicação). O maior número médio de brotos foi obtido com as luzes verde e vermelha (3,55 e 3,14 brotos, respectivamente) (Tabela 1). Resultados semelhantes foram obtidos por Casano (1995) e Marks \& Simpson (1999), que utilizaram o mesmo tipo de filtro nos seus trabalhos. O primeiro autor, no cultivo in vitro do porta-enxerto de macieira MM106, verificou que a luz verde proporcionou a maior proliferação de brotos. Os outros dois autores, no cultivo de Disanthus cercidifolius, cultivares de Rhododendron e Crataegus oxyacantha, concluíram que a luz vermelha promoveu a maior brotação. Luca et al. (2001) verificaram que as plantas de Alternanthera brasiliana L., cultivadas sob luz verde, formaram até quatro brotos por explante, enquanto sob luz vermelha, branca e no escuro, o número de brotos por explante foi de apenas dois. A luz vermelha, em comparação à luz branca, também incrementou o número de brotos axilares em culturas in vitro de Rhododendron, Potentilla e Spiraea (Norton et al., 1988).
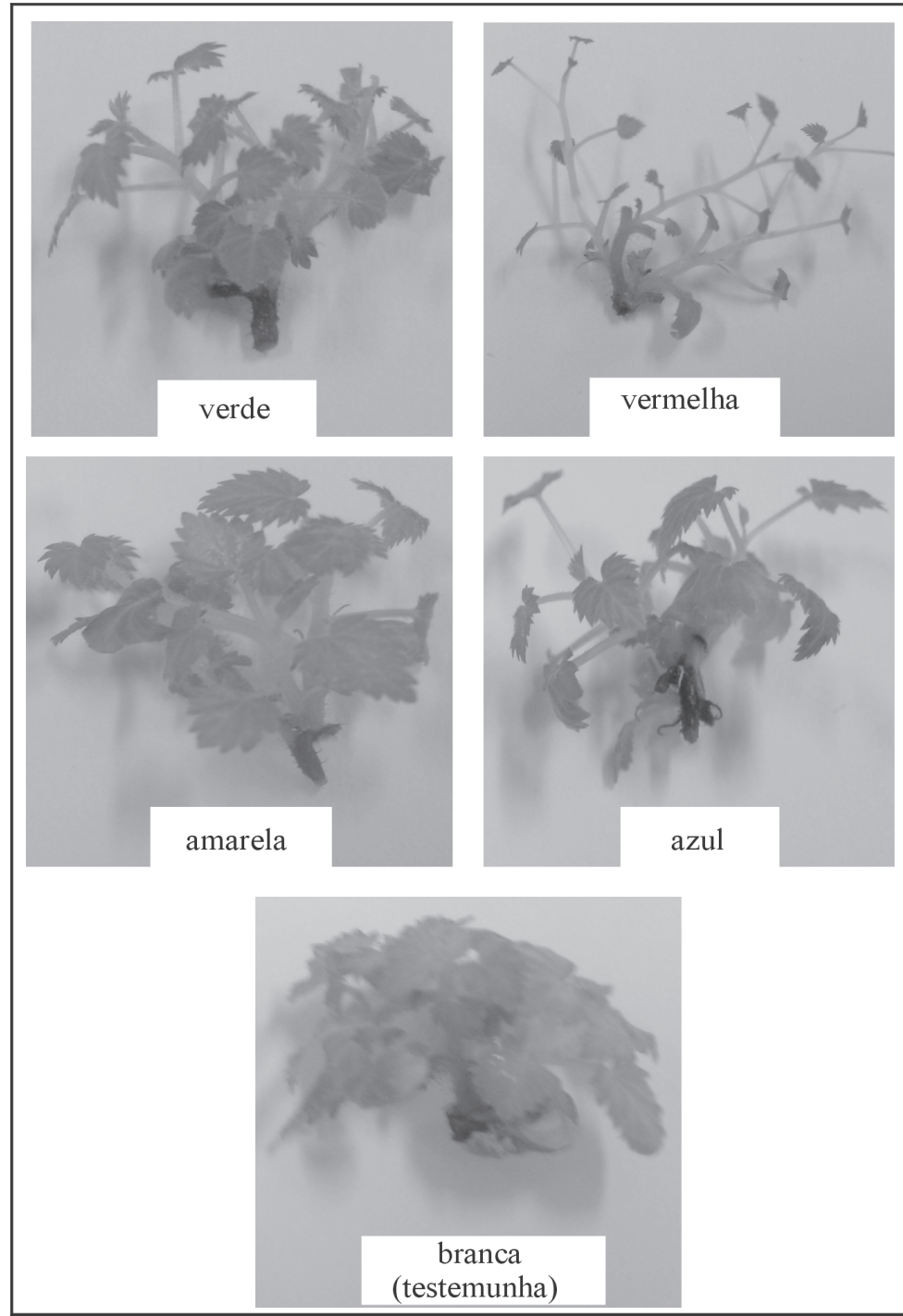

FIGURA 1 - Aspecto geral dos brotos de framboeseira (Rubus idaeus L.) 'Batum', aos 45 dias de multiplicação in vitro, em função do tipo de luz. UFPel, Pelotas - RS. 2004.

O aspecto geral dos brotos crescidos sob a luz vermelha distinguiu-se morfologicamente daqueles crescidos sob as outras qualidades da luz, apresentando as folhas pequenas, os brotos finos e os entrenós alongados (Figura 1). Estes resultados corroboram os relatos de Morini \& Muleo (2003), de que a exposição contínua ao escuro e a faixa de luz do vermelho-longo promovem modificações na morfologia da cultura, entre as quais, menor expansão das folhas, entrenós alongados e síntese de clorofila, carotenóides e antocianinas, muitas vezes reduzida. Plantas de Alternanthera brasiliana L., cultivadas sob luz vermelha, também apresentaram menor área foliar (Luca et al., 2001). Na multiplicação in vitro do porta-enxerto de Prunus GF 677, Morini \& Muleo (2003) obtiveram maior comprimento dos entrenós nas plantas mantidas sob a luz vermelha, apesar de o maior número de brotos por explante, neste caso, ter sido obtido com a luz branca. Marks \& Simpson (1999) também mencionam que a utilização da luz vermelha estimula o alongamento dos brotos em espécies lenhosas. Kim et al. (2004) também

TABELA 1 - Número médio de brotos, número médio de folhas e taxa de multiplicação de framboeseira (Rubus idaeus L.) ‘Batum’, aos 45 dias de multiplicação in vitro, em função do tipo de luz. UFPel, Pelotas - RS. 2004.

\begin{tabular}{|c|c|c|c|}
\hline Tipo de luz & Número médio de brotos* & Número médio de folhas* & Taxa de multiplicação* \\
\hline Verde & $3,55 a$ & $23,74 a$ & $8,10 \mathrm{a}$ \\
\hline Vermelha & $3,14 \mathrm{a}$ & $19,98 b$ & $6,91 b$ \\
\hline Amarela & $2,50 \mathrm{~b}$ & $17,86 \mathrm{bc}$ & $6,16 \mathrm{bc}$ \\
\hline Azul & $2,68 b$ & $16,06 \mathrm{c}$ & $5,56 \mathrm{c}$ \\
\hline Branca (testemunha) & $2,63 b$ & $15,54 \mathrm{c}$ & $5,32 \mathrm{c}$ \\
\hline $\mathrm{CV}(\%)$ & 3,74 & 5,86 & 11,42 \\
\hline
\end{tabular}

* Médias seguidas pelas mesmas letras não diferem estatisticamente entre si, pelo teste de Duncan, ao nível de 5\% de probabilidade. 
verificaram alongamento dos entrenós de crisântemos cultivados sob luz na faixa do vermelho e vermelho-longo. Segundo estes autores, o alongamento dos brotos pode ser promovido ou inibido por meio do controle da qualidade luminosa e da proporção entre as diferentes faixas de luz.

A luz verde também favoreceu a obtenção de maior número médio de folhas e maior taxa de multiplicação (Tabela 1). Resultado distinto foi obtido por Luca et al. (2001), onde as plantas de Alternanthera brasiliana L., cultivadas sob luz azul, apresentaram o maior número de folhas (aproximadamente três folhas), seguida pelas submetidas às luzes branca e verde (aproximadamente 2,5 e 2 folhas, respectivamente). Como a função do tipo de luz no crescimento e desenvolvimento das plantas ainda não está bem esclarecida (Hahn et al., 2000), ela pode variar com a espécie de planta, o estádio de crescimento, as condições ambientais, a composição do meio de cultura e a ventilação. Por essa razão, estudos detalhados são necessários para correlacionar o tipo de luz às condições de crescimento e, inclusive, aos objetivos do cultivo.

Apesar de a luz branca ser a mais utilizada na cultura de tecidos, neste trabalho, verificou-se que os melhores resultados foram obtidos com a luz verde, e para o número médio de brotos, também com a vermelha. De acordo com Taiz \& Zeiger (2004), apenas os fótons de comprimento de onda de 400 a 700nm são utilizados na fotossíntese e cerca de 85 a 90\% dessa radiação fotossinteticamente ativa é absorvida pela folha, sendo o restante refletido na superfície foliar ou transmitido através da folha. Segundo Salisbury \& Ross (1992), as folhas irradiadas com luz branca absorvem mais as longitudes de ondas azul e vermelha e grande parte do verde. Isto provavelmente justifique os resultados obtidos neste trabalho, apesar de a luz azul não ter proporcionado os melhores resultados.

\section{CONCLUSÕES}

A eficiência da multiplicação in vitro de framboeseira 'Batum' é aumentada com a utilização da luz verde. A luz vermelha também incrementa o número médio de brotos; no entanto, sua morfologia é modificada (com menor expansão das folhas, brotos finos e entrenós alongados).

\section{REFERÊNCIAS}

ALÁRCON, J.S.M. Propagación de arándano y frambueso rojo. In: SEMINÁRIO BRASILEIRO SOBRE PEQUENAS FRUTAS, 2., 2004, Vacaria, RS. Anais... Bento Gonçalves: Embrapa Uva e Vinho, 2004. p.31-38.

BARALDI, R.; ROSSI, F.; LERCARI, B. In vitro shoot development of Prunus GF 655-2: interaction between light and benzyladenine. Physiologia Plantarum, Copenhagen, v.74, p.440-443, 1988.

CASANO, S. Effetti della qualitá della luce sulla morfogenesi di specie arboree da frutto coltivate in vitro. Pisa, 1995. 97f. Dissertazione (Dottorato di Ricerca in Ortoflorofrutticoltura), Universitá Degli Studi di Pisa, Pisa, 1995.

FELIPPE, G.M. Fotomorfogênese. In: FERRI, M.G. (coord.) Fisiologia Vegetal 2. São Paulo: EPU, 2.ed., 1986. p.231-280.
GRATTAPAGLIA, D.; MACHADO, M.A. Micropropagação. In: TORRES, A.C.; CALDAS, L.S.; BUSO, J.A. Cultura de tecidos e transformação genética de plantas. Brasília: SPI/Embrapa-CNPH, v.1. 1998. p.183-260.

HAHN, E.J.; KOZAI, T.; PAEK, K.Y. Blue and red light emitting diodes with or without sucrose and ventilation affect in vitro growth of Rehmannia glutinosa plantlets. Journal of Plant Biology, New York, v.43, p.247-250, 2000.

KIM, S.J.; HAHN, E.J.; HEO, J.W.; PAEK, K.Y. Effects of LEDs on net photosynthetic rate, growth and leaf stomata of chrysanthemum plantlets in vitro. Scientia Horticulturae, Amsterdam, v.101, n.1-2, p.143-151, 2004.

KODYM, A.; ZAPATA-ARIAS, F.J. Natural light as an alternative light source for the in vitro culture of banana (Musa acuminata cv. 'Grande Naine'). Plant Cell, Tissue and Organ Culture, The Hague, v.55, p.141-145, 1999.

LUCA, R.L.; MACEDO,A.F.; CECHINEL, V.F.; LAGE, C.L.S.; ESQUIBEL, M.A. Ação de diferentes faixas do espectro luminoso na otimização da produção de Alternanthera brasiliana L., uma planta medicinal. In: ENCUENTRO LATINOAMERICANO DE BIOTECNOLOGÍA VEGETAL, 4., 2001, Goiânia-GO. Anais... Goiânia: Redbio, 2001.6p.

MARKS, T.R.; SIMPSON, S.E. Effect of irradiance on shoot development in vitro. Plant Growth Regulator, Farnham Royal, v.28, n.2, p.133-142, 1999.

MORINI, S.; MULEO, R. Effects of light quality on micropropagation of woody species. In: JAIN, S.M.; ISHII, K. Micropropagation of woody trees and fruits. Dordrecht, Kluwer Academic Publishers, 2003. p.3-35.

MURASHIGE, T.; SKOOG, F. A revised medium for rapid growth and biossay with tobacco tissue cultures. Physiologia Plantarum, Copenhagen, v.15, p.473-497, 1962.

NORTON, C.R.; NORTON, M.E.; HERRINGTON, T.; PHILLIPS, D. Light quality and light pipe in the micropropagation of woody ornamental plants. Acta Horticulturae, The Hague, n.226, p.413-416, 1988.

PAGOT, E.; HOFFMANN, A. Produção de pequenas frutas no Brasil. In: SEMINÁRIO BRASILEIRO SOBRE PEQUENAS FRUTAS, 1. 2003, Vacaria-RS. Anais... Bento Gonçalves: Embrapa Uva e Vinho (Documentos 37), 2003.64p.

RASEIRA, M.C.B.; GONÇALVES, E.D.; TREVISAN, R.; ANTUNES, L.E.C. Aspectos técnicos da cultura da framboeseira. Pelotas: Embrapa Clima Temperado (Documentos 120), 2004. 22p.

ROSSI, A.; RUFATO, L.; FIASCHI, G.; MORINI, S.; LORETI, F. Efeito de diferentes tratamentos de luz na micropropagação de porta-enxertos para Prunus spp. da série de clones I.S. In: CONGRESSO BRASILEIRO DE FRUTICULTURA, 17., 2002, Belém-PA. Anais... Belém: Sociedade Brasileira de Fruticultura, 2002.5p.

SALISBURY, F.B.; ROSS, C.W. Relación fotosíntesis - transpiración. In: Fisiología vegetal. México, Grupo Editorial Iberoamérica, 1992. p.71-100.

TAIZ, L.; ZEIGER, E. Fotossíntese: considerações fisiológicas e ecológicas. In: Fisiologia vegetal. 3.ed., Porto Alegre: Artmed, 2004. p.199-219.

ZONTA, E.P.; MACHADO, A.A. SANEST - Sistema de análise estatística para microcomputadores. Pelotas: DMEC/IFM/UFPel, 1987. 138p. 